\title{
Effectiveness of bisphosphonates on nonvertebral and hip fractures in the first year of therapy: The risedronate and alendronate (REAL) cohort study
}

\author{
S. L. Silverman • N. B. Watts • P. D. Delmas • \\ J. L. Lange $\cdot$ R. Lindsay
}

Received: 15 September 2006 / Accepted: 17 October 2006/ Published online: 15 November 2006

(C) International Osteoporosis Foundation and National Osteoporosis Foundation 2006

\begin{abstract}
Introduction Randomized clinical trials have shown that risedronate and alendronate reduce fractures among women with osteoporosis. The aim of this observational study was to observe, in clinical practice, the incidence of hip and nonvertebral fractures among women in the year following initiation of once-a-week dosing of either risedronate or alendronate.

Methods Using records of health service utilization from July 2002 through September 2004, we created two cohorts:
\end{abstract}

This work was presented in part at the 28th annual meeting of the American Society for Bone and Mineral Research, Philadelphia, PA; September 15-19, 2006.

S. L. Silverman

Cedars-Sinai Medical Center and David Geffen School

of Medicine at the University of California Los Angeles,

Los Angeles, CA, USA

\section{N. B. Watts}

Bone Health and Osteoporosis Center, University of Cincinnati,

Cincinnati, OH, USA

P. D. Delmas

INSERM Unit 403, Université Claude Bernard Lyon 1,

Lyon, France

\section{J. L. Lange}

P\&G Pharmaceuticals,

Mason, OH, USA

R. Lindsay

Helen Hayes Hospital,

West Haverstraw, NY, USA

S. L. Silverman $(\bowtie)$

8641 Wilshire Blvd., Suite 301,

Beverly Hills, CA 90211, USA

e-mail: stuarts@omcresearch.org women (ages 65 and over) receiving risedronate $(n=12,215)$ or alendronate $(n=21,615)$. Cox proportional hazard modeling was used to compare the annual incidence of nonvertebral fractures and of hip fractures between cohorts, adjusting for potential differences in risk factors for fractures. Results There were 507 nonvertebral fractures and 109 hip fractures. Through one year of therapy, the incidence of nonvertebral fractures in the risedronate cohort $(2.0 \%)$ was $18 \%$ lower $(95 \%$ CI $2 \%-32 \%)$ than in the alendronate cohort $(2.3 \%)$. The incidence of hip fractures in the risedronate cohort $(0.4 \%)$ was $43 \%$ lower $(95 \%$ CI $13 \%-$ $63 \%)$ than in the alendronate cohort $(0.6 \%)$. These results were consistent across a number of sensitivity analyses.

Conclusion Patients receiving risedronate have lower rates of hip and nonvertebral fractures during their first year of therapy than patients receiving alendronate.

Keywords Bisphosphonates · Epidemiology

Hip fractures · Nonvertebral fractures · Osteoporosis

\section{Introduction}

Osteoporosis, a common skeletal disease in older populations, leads to more than a million fractures annually in the United States [1]. Nonvertebral fractures represent $75 \%$ of osteoporotic fractures seen in clinical practice [2]. The incidence of nonvertebral fractures, especially at the hip, increases rapidly with age [3]. In order to prevent these fractures, US clinical guidelines recommend that candidates for osteoporosis therapy be identified by screening the bone mineral density of all woman ages 65 and over (age 60 for high risk populations) [4].

Oral bisphosphonates are currently the most common therapy for osteoporosis [5]. While the three most utilized 
bisphosphonates (alendronate, risedronate, ibandronate) approved by the Food and Drug Administration have been shown to reduce vertebral fractures in randomized clinical trials, it is unknown if these three are equally effective in reducing nonvertebral fractures of real-world patients in clinical practice. A comparison of the results from the randomized clinical trials of each bisphosphonate, though limited by methodological differences between trials, suggests potential differences in degree of fracture reduction across bisphosphonates. In the primary analyses of the trials that followed patients for at least 3 years, risedronate significantly reduced the incidence of nonvertebral fractures by up to $39 \%[6,7]$; alendronate reduced the incidence of nonvertebral fractures by up to $21 \%$ [8-10]; ibandronate did not reduce nonvertebral fractures [11]. Post-hoc analyses of these trial data suggest that there are differences in the onset of fracture reduction. In those analyses, reduction of nonvertebral fractures began at 6 months for $5 \mathrm{mg}$ daily dosing of risedronate [12] and at either 12 months (when fractures were recorded as adverse events) for $10 \mathrm{mg}$ daily dosing of alendronate [13] or 24 months for $5 \mathrm{mg}$ daily dosing of alendronate [14]. These possible differences in both the amount and the onset of fracture reduction between the bisphosphonates could arise from their differences in structure, potency, and binding properties [15].

The only direct comparison of bisphosphonates in a randomized clinical trial is based on surrogate endpoints (e.g., changes in bone mineral density and markers of bone turnover) [16]. However, the association between changes in these surrogates and subsequent fracture reduction is not consistent across studies [17, 18]. Unlike randomized clinical trials based on surrogate endpoints, observational studies of large populations provide the opportunity to use major disease endpoints (e.g., hip fracture) as the outcome of interest. The limitation of observational studies can be misleading results from bias arising from non-randomized treatment groups. This bias can be accounted for in part by statistically adjusting for known risk differences between groups. Furthermore, when different therapies are available to be prescribed for the same indication, there is at least some expectation of similarity in prognostic factors between treatment groups occurring naturally [19]. For example, observational studies have compared both the many antihypertensive drug therapies and many statins for reducing the disease endpoint of myocardial infarctions [20,21].

Since the once-a-week dosing regimens of both risedronate and alendronate have been available in the US since 2002 , there is now an opportunity to observe their effect on reducing fractures in a large population of patients seen in clinical practice. Hence, we conducted an observational study across multiple US health plans to observe the incidence of hip and nonvertebral fractures among women ages 65 and over following initiation of therapy with oncea-week dosing of either risedronate or alendronate.

\section{Methods}

The RisedronatE and ALendronate (REAL) cohort study was a retrospective observation of bisphosphonate patients within healthcare utilization records in the United States. The analysis plan was based upon an earlier report [22]. All authors had access to the data. For assurance of reproducibility [23], the analyses were independently replicated by the respective organizations of the authors. The reporting of this study is consistent with the STROBE guidelines [24].

Data source

The data source was commercially available datasets of healthcare utilization from the 1 health plan within Ingenix Lab/Rx (Eden Prairie, MN; data through June 2004) and the 100 health plans of employers within MedStat Marketscan (Ann Arbor, MI; data through September 2004). These datasets contain a longitudinal history of patient-specific data including demographic information (sex, age, dates of dataset inclusion), clinical encounters (inpatient and outpatient services by associated procedures and diagnoses specified by the International Classification of Diseases, Ninth Revision, Clinical Modification (ICD-9-CM)), and outpatient pharmaceutical dispensations (retail and mail order specified by the national drug code (NDC)). To maximize sample size, the two datasets were combined for all analyses. At the time of data extraction for the current study, the combined datasets contained 12 million persons across 34 states in the US.

\section{Study population}

Within the data source, candidates for study inclusion were all women aged 65 and older with any use of once-a-week dosing of risedronate $(35 \mathrm{mg}$; Actonel, $\mathrm{P} \& \mathrm{G}$ Pharmaceuticals) or once-a-week dosing of alendronate ( 35 or $70 \mathrm{mg}$; Fosamax, MSD) after July 2002, a date corresponding with contemporaneous commercial availability of once-a-week versions of both therapies (Fig. 1). Patient exclusion criteria and rationale were: 1) less than 6 months (182 days) of health plan enrollment before their first bisphosphonate use after July 2002, a history period to measure baseline fracture risk; 2) less than 3 months (92 days) of health plan enrollment after their first bisphosphonate use, a minimum observation period with expectation of any fracture reduction (based on post-hoc analyses of clinical 
Fig. 1 Identification of the study population

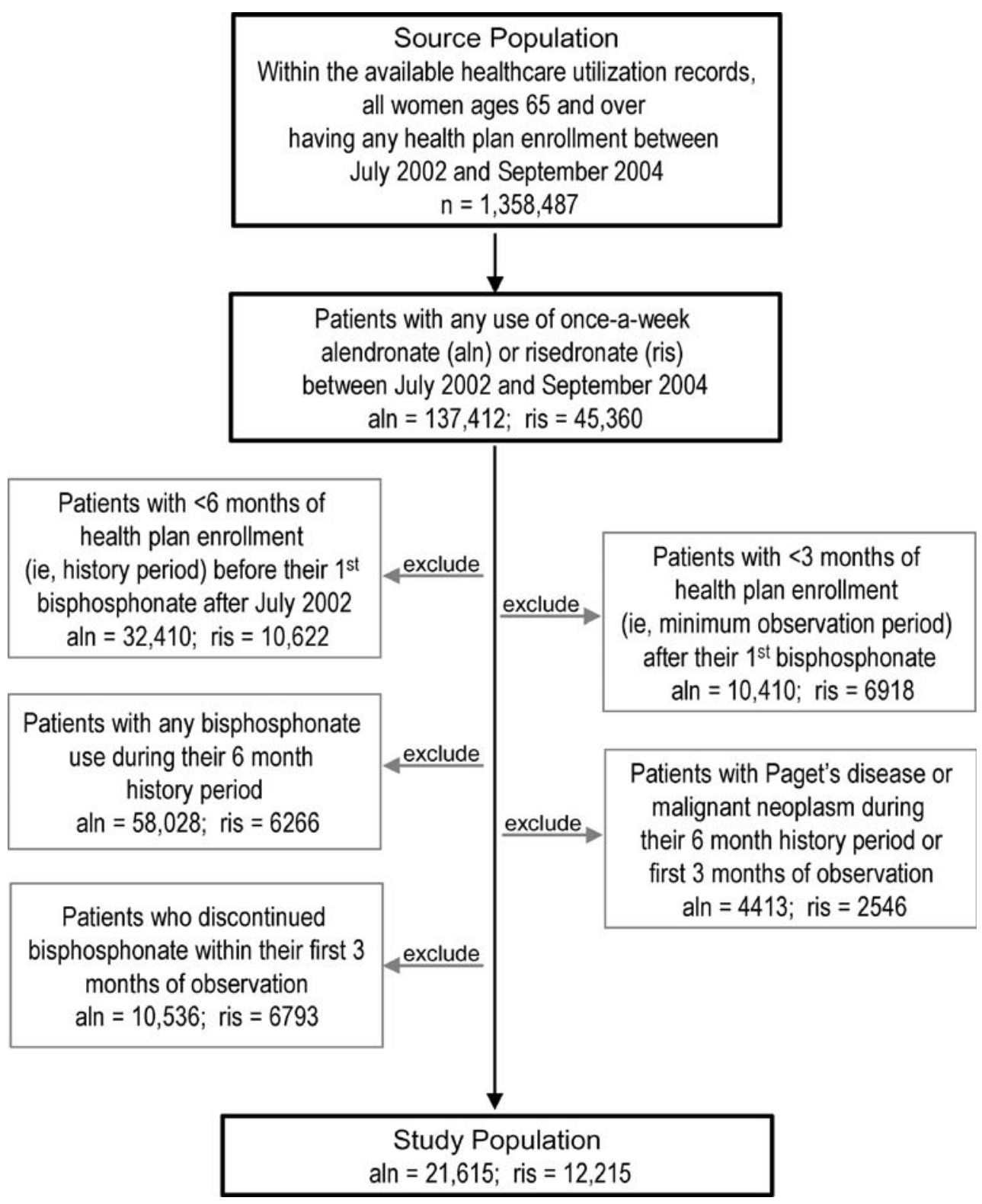

trials $[12,14]) ; 3$ ) any bisphosphonate use (daily, weekly, or Paget's doses) during their 6 month history period, to include only patients who are new users of bisphosphonates; 4) diagnosis of malignant neoplasm, ICD-9-CM 140 - 208; or Paget's disease, ICD-9-CM 731.0 during either the 6 month history period or first 3 months of observation, to exclude patients with fracture risk not related to osteoporosis; and 5) discontinued therapy within the first 3 months, a minimum period of therapy adherence.

\section{Length of observation}

Observation for a subject was censored at one of following end points, whichever occurred first: date of fracture, 12 months after date of first bisphosphonate prescription, end date of health plan enrollment, date of switch between bisphosphonate therapies or end date of therapy adherence. Adherence was measured as a function of the gaps between refills, which provides the best available measure within datasets of medical claims [25]. Once the gap between the completion of a 30-day supply and the start of a new prescription exceeded 15 days, the end date of therapy adherence was the prescription date before gap plus 45 days. For a 90-day supply, a gap of 45 days was allowed between completion and a new prescription, the end date of therapy adherence was the prescription date before gap plus 135 days. For the last prescription, the end date of therapy adherence was the date of last prescription plus 45 days for a 30-day supply and date of last prescription plus 135 days for a 90-day supply. 
Fracture outcomes

From the data source, two outcomes were identified: subjects with nonvertebral fractures collectively (hip, wrist, humerus, clavicle, pelvis, leg - sites previously specified [12]) and subjects with a hip fracture. Vertebral fractures were not included because the majority of them do not come to clinical attention and thus not systematically captured in the data source. In an attempt to identify incident fractures more likely related to osteoporosis, we used a series of exclusion criteria (Table 1). A total of 109 hip and 507 nonvertebral fracture patients were available for analyses.

\section{Statistical analyses}

To assess the comparability of baseline characteristics (see Table 2 for specific definitions of demographic characteristics and health history) between the risedronate and alendronate cohorts, the chi-square test was used for dichotomous variables and the Wilcoxon rank sum test was used for continuous variables.

For the primary analysis, the main outcome measures were the 6 and 12 month incidence of nonvertebral fractures and hip fractures. Cox proportional hazard modeling (PROC PHREG, SAS Institute, Cary, NC) was used to compare the incidence of fractures between risedronate and alendronate cohorts, adjusting for potential differences in measurable risk factors for fractures. A parsimonious model for each outcome was developed to enhance precision of the parameter estimates and interpretation of results. The selection of variables to be included in the model was based on forward selection. These models were checked against models based on backward selection. The appropriateness of the proportional hazard assumption was assessed by graphical and numerical methods (ASSESS statement, SAS Institute).

In order to evaluate if the results of the primary analysis were dependent on methodology, sensitivity analysis were used to compare the incidence of fractures between risedronate and alendronate cohorts. These methods included: (1) an intent-to-treat analysis that observed all subjects for 12 months regardless of therapy adherence; (2) a proportional hazard model using the propensity score to adjust for differences in baseline fracture risk between cohorts; (3) use of different inclusion criteria for the study population; (4) use of different inclusion criteria for the study outcomes (see Fig. 5 for specifics).

\section{Results}

The risedronate cohort included 12,215 subjects on once-aweek dosing of $35 \mathrm{mg}$ followed for a mean of 226 days on therapy. $37 \%$ of this cohort was censored before 12 months because of the end date of available data and $41 \%$ was censored for an end in therapy adherence. The alendronate cohort included 21,615 subjects on once-a-week dosing of $35 \mathrm{mg}(8 \%)$ or $70 \mathrm{mg}(92 \%)$ followed for a mean of 238 days on therapy. $33 \%$ of this cohort was censored before 12 months because of the end date of available data and $41 \%$ was censored for an end in therapy adherence. Upon start of bisphosphonate therapy, the two cohorts were different in several baseline characteristics (Table 2). Statistically, the risedronate cohort was older, had more concomitant medications, had more use of glucocorticoids,

Table 1 Identification of fractures outcomes in the study population $(n=33,830)$

\begin{tabular}{|c|c|c|}
\hline & $\begin{array}{l}\text { Hip } \\
\text { fracture }^{\mathrm{a}}\end{array}$ & $\begin{array}{l}\text { Nonvertebral } \\
\text { fracture }^{\mathrm{b}}\end{array}$ \\
\hline Subjects with a medical claim for fracture during the observation period after initial bisphosphonate. & 135 & 923 \\
\hline $\begin{array}{l}\text { Exclusion of medical claim if a fracture at the same site both before and after start of bisphosphonate therapy; } \\
\text { in order to increase the likelihood of including only new fractures. }\end{array}$ & -16 & -368 \\
\hline $\begin{array}{l}\text { Exclusion of medical claim if a fracture at an unspecified site }{ }^{\mathrm{c}} \text { before the start of bisphosphonate therapy; } \\
\text { in order to increase the likelihood of including only new fractures. }\end{array}$ & -2 & -6 \\
\hline $\begin{array}{l}\text { Exclusion of medical claim if an open fracture }{ }^{\mathrm{d}} \text {; in order to decrease the likelihood of including traumatic } \\
\text { fractures. }\end{array}$ & -3 & -11 \\
\hline $\begin{array}{l}\text { Exclusion of medical claim if documented cause (E-codes) of injury is other than an accidental falle; } \\
\text { in order to decrease the likelihood of including traumatic fractures. }\end{array}$ & -5 & -31 \\
\hline Subjects with a fracture outcome & 109 & 507 \\
\hline
\end{tabular}

${ }^{a}$ Inpatient ICD-9-CM codes (820.x, 733.14)

${ }^{\mathrm{b}}$ In addition to inpatient hip fractures, inpatient and outpatient ICD-9-CM codes for fracture of the wrist (813.x, 733.12), humerus

(812.x, 733.11), clavicle (810.x), pelvis (808.x), and leg (821.x, 823.x, 733.15, 733.16)

${ }^{\mathrm{c}}$ ICD-9-CM code $(733.10$ or 733.19$)$

${ }^{\mathrm{d}}$ ICD-9-CM code that is not $733.1 \mathrm{x}$ or where the 4 th digit is not $=.1, .3, .5, .9$

e ICD-9-CM code with "E" classification (E880 - E888) for accidental falls 
Table 2 Comparison of baseline characteristics between cohorts in study

\begin{tabular}{|c|c|c|c|}
\hline \multirow[b]{2}{*}{ Characteristic } & \multicolumn{3}{|l|}{ Cohorts } \\
\hline & Risedronate & Alendronate & p-value \\
\hline Number of women subjects & 12,215 & 21,615 & \\
\hline \multicolumn{4}{|l|}{ Duration of observation period } \\
\hline Days (mean) & 226 & 238 & $<0.001$ \\
\hline \multicolumn{4}{|l|}{ Age at study entry } \\
\hline Years \& months (mean) & $74 \& 10$ & $74 \& 7$ & $<0.001$ \\
\hline Ages $65-74(\%)$ & 53.5 & 52.4 & \\
\hline Ages $75-84(\%)$ & 36.8 & 36.7 & \\
\hline Ages 85 and over $(\%)$ & 9.7 & 11.0 & \\
\hline \multicolumn{4}{|l|}{ Medications - 6 month history ${ }^{a}$} \\
\hline Concomitant medications (mean) ${ }^{\mathrm{b}}$ & 4.0 & 3.6 & $<0.001$ \\
\hline Gastrointestinal medication use $(\%)^{c}$ & 26.2 & 20.1 & $<0.001$ \\
\hline Estrogen use $(\%)^{\mathrm{d}}$ & 17.2 & 16.5 & 0.08 \\
\hline Other non-estrogen anti-osteoporotic use $(\%)^{\mathrm{e}}$ & 15.6 & 11.0 & $<0.001$ \\
\hline Glucocorticosteroid use $(\%)^{\mathrm{f}}$ & 10.3 & 8.5 & $<0.001$ \\
\hline \multicolumn{4}{|l|}{ Medical encounters - 6 month history ${ }^{a}$} \\
\hline Office visits (mean) & 5.6 & 5.1 & $<0.001$ \\
\hline Hospitalization (\%) & 8.2 & 8.2 & 0.87 \\
\hline Osteoporosis diagnosis $(\%)^{\mathrm{g}}$ & 37.7 & 33.8 & $<0.001$ \\
\hline Osteopenia diagnosis $(\%)^{\mathrm{h}}$ & 12.5 & 10.5 & $<0.001$ \\
\hline Bone densitometry procedure $(\%)^{\mathrm{i}}$ & 47.4 & 41.5 & $<0.001$ \\
\hline Gastrointestinal diagnosis $(\%)^{\mathrm{j}}$ & 15.4 & 12.3 & $<0.001$ \\
\hline Rheumatoid arthritis diagnosis $(\%)^{\mathrm{k}}$ & 2.7 & 2.3 & 0.01 \\
\hline
\end{tabular}

${ }^{a}$ Six months before and including date of starting first bisphosphonate prescription

${ }^{\mathrm{b}}$ Based on number of therapeutic classes with a prescription [34]

${ }^{\mathrm{c}}$ Based on NDC codes for at least one prescription for either: H2 antagonists (ranitidine, cimetidine, famotidine, nizatidine); Proton pump inhibitors (omeprazole, esomeprazole, lansoprazole, pantoprazole); Cytoprotectives (misoprostol, sucralfate) [35]

${ }^{\mathrm{d}}$ Based on NDC codes for at least one prescription of estradiol, conjugated estrogen, esterified estrogen, or estropipate

${ }^{\mathrm{e}}$ Based on NDC codes for at least one prescription of calcitonin or raloxifene

${ }^{\mathrm{f}}$ Based on NDC codes for at least one prescription for triamcinolone, prednisone, prednisolone, methylprednisolone, dexamethasone, budesonide, betamethasone, cortisone, or hydrocortisone

g ICD-9 733.0x

${ }^{\mathrm{h}}$ ICD-9 733.90 and no record of $733.0 \mathrm{x}$

${ }^{\mathrm{i}} \mathrm{CPT}$ 76070, 76075, 76076, 78350, 78351, ICD-9 88.98

${ }^{\mathrm{j}}$ Multiple ICD-9 codes [36]

${ }^{\mathrm{k}}$ ICD-9 714.0

and had more patients with rheumatoid arthritis than the alendronate cohort - characteristics that may increase fracture risk. Conversely, the risedronate cohort also had greater past use of calcitonin or raloxifene - a characteristic that may decrease fracture risk. Within the 12 months prior to the initiation of bisphosphonate therapy, similar percentages of the two cohorts had a diagnosis for a nonvertebral fracture and a clinical vertebral fracture, while a statistically larger percentage of the risedronate cohort had a diagnosis for a hip fracture than the alendronate cohort (Fig. 2).

During the 12 months of observation after the start of bisphosphonate therapy, 507 subjects had nonvertebral fractures. The site of nonvertebral fracture was wrist $(30 \%)$, hip $(21 \%)$, leg $(17 \%)$, pelvis $(15 \%)$, humerus $(14 \%)$, and clavicle (3\%). For the 109 women hospitalized with a hip fracture, the skeletal sites were intertrochanteric
(46\%), transcervical (28\%), unspecified $(20 \%)$, and trochanteric or subtrochanteric $(6 \%)$.

For the primary analysis of nonvertebral fractures, the fracture incidence was similar between the risedronate and alendronate cohorts over the first 3 months of therapy (Fig. 3). After 6 months of therapy, the risedronate cohort had a $19 \%$ lower $(95 \%$ CI $0 \%-35 \%$, p-value $=0.05)$ incidence of nonvertebral fracture than the alendronate cohort. After 12 months of therapy, the risedronate cohort had an $18 \%$ lower $(95 \%$ CI $2 \%-32 \%$, p-value $=0.03)$ incidence of nonvertebral fracture than the alendronate cohort (Table 3).

For the primary analysis of hip fractures, the fracture incidence was similar between the risedronate and alendronate cohorts over the first 3 months of therapy (Fig. 4). After 6 months of therapy, the risedronate cohort had a $46 \%$ lower $(95 \%$ CI $9 \%-68 \%$, p-value $=0.02)$ incidence of 
Fig. 2 Percent of patients with a clinical diagnosis of fracture before initiation of bisphosphonate therapy. ${ }^{1} \mathrm{ICD}-9$ codes 808.x, 810.x, 812.x, 813.x, 820.x, 821.x, 823.x, 733.10, $-.12,-.14,-.19 ;{ }^{2}$ ICD-9 codes 820.x, 733.14; ${ }^{3}$ ICD-9 codes 805.x, 806.x, 733.13; ${ }^{4}$ Subset (81\%) of study population with available 12 month history. *Statistical difference $(\mathrm{p}<0.05)$ between cohorts

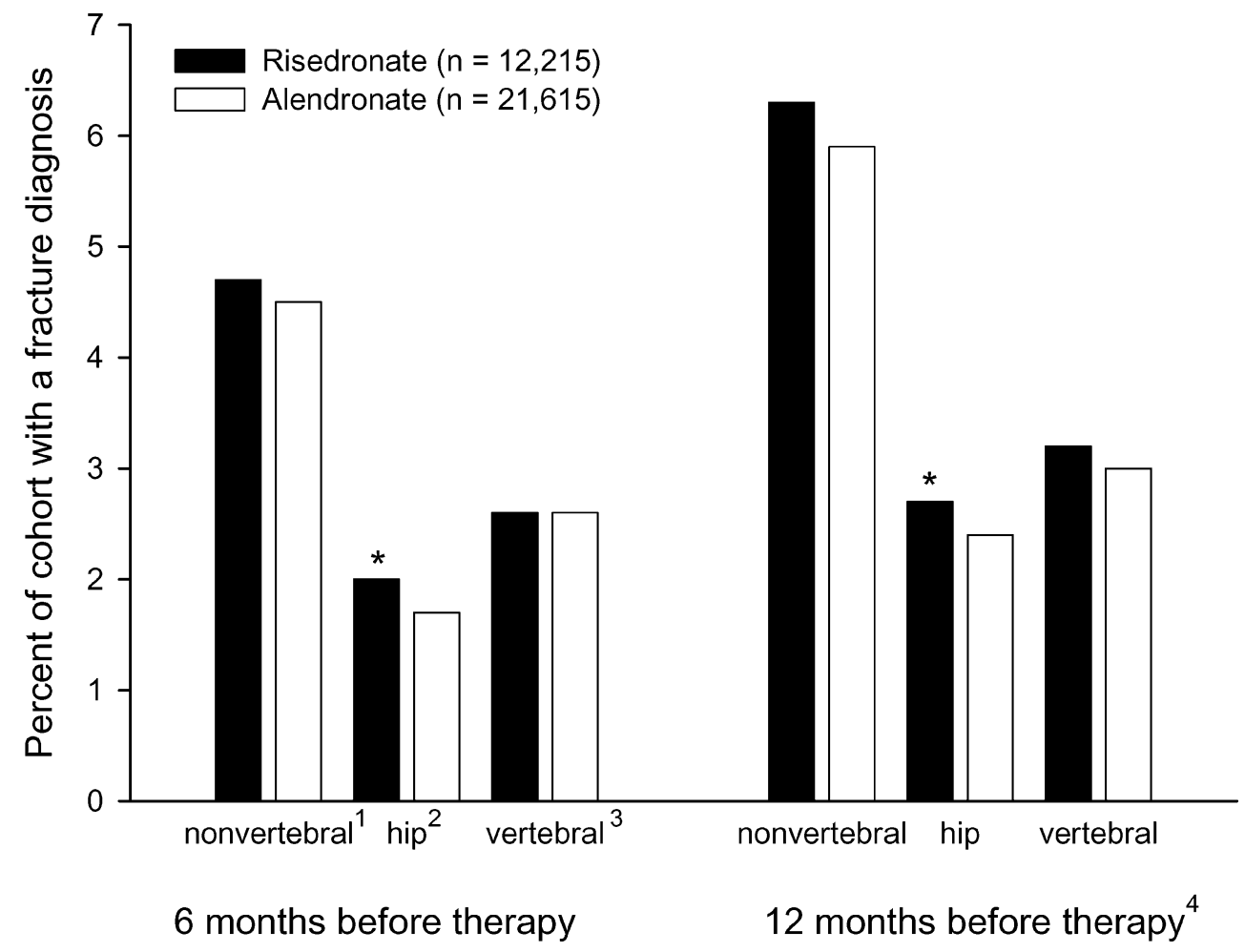

hip fracture than the alendronate cohort. After 12 months of therapy, the risedronate cohort had a $43 \%$ lower $(95 \%$ CI $13 \%-63 \%$, p-value $=0.01)$ incidence of hip fracture than the alendronate cohort (Table 3 ).

These differences between the risedronate and alendronate cohorts in the incidence of fractures were consistent across other methods of analysis (Fig. 5). Depending on the method, the risedronate cohort had an estimated $6 \%$ to $23 \%$ lower incidence of nonvertebral fractures and an estimated $30 \%$ to $50 \%$ lower incidence of hip fractures than the alendronate cohort through 12 months of therapy. All of these other estimates were within the confidence intervals of the primary analyses.
Fig. 3 Cumulative incidence of nonvertebral fractures in patients treated with alendronate or risedronate for up to 1 year

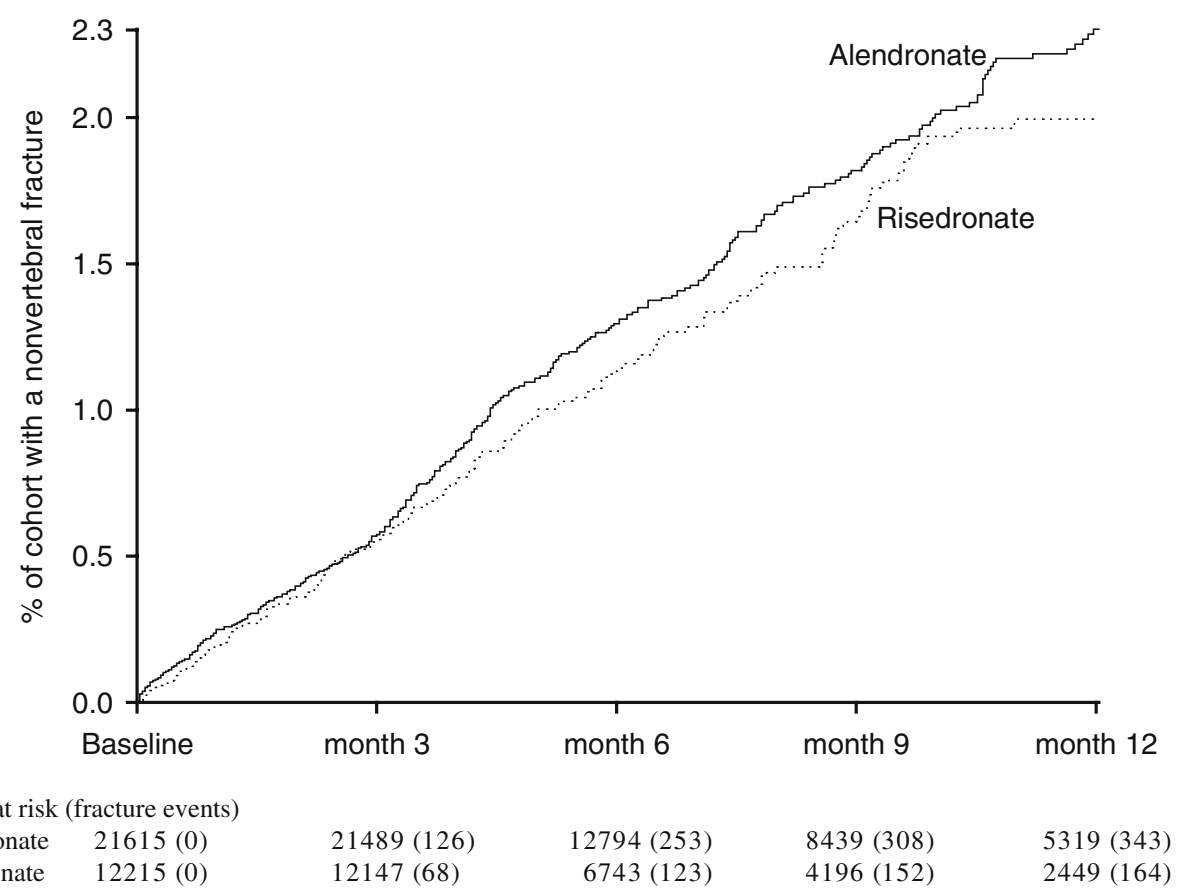


Table 3 Cumulative incidence of fractures during therapy

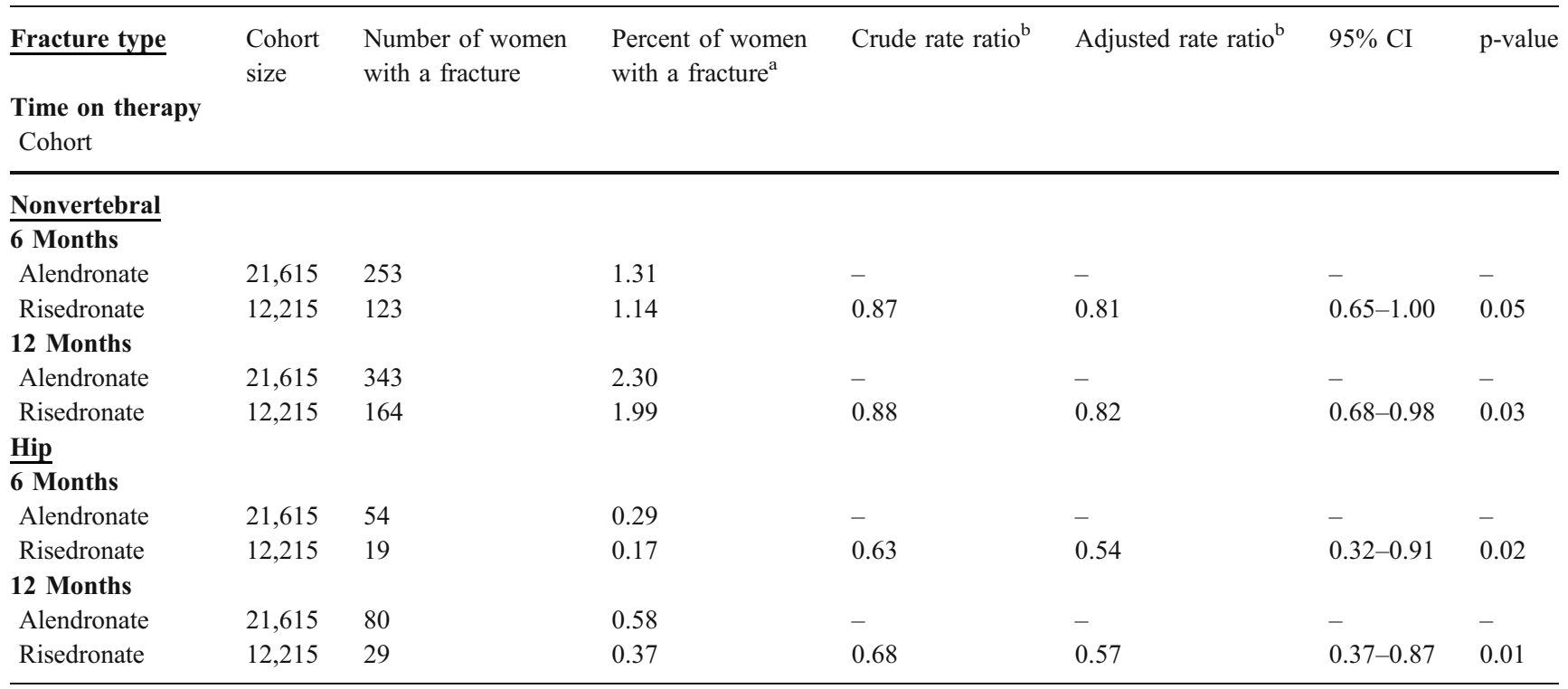

$\mathrm{CI}=$ confidence interval of adjusted rate ratio

${ }^{\text {a }}$ Proportion is based on Kaplan-Meier estimate of the survival function.

${ }^{\mathrm{b}}$ Based on Cox regression model.

${ }^{\mathrm{c}}$ Based on Cox regression model. Variables selected by forward stepwise selection where criteria for selection $\mathrm{p}<0.1$. Model for nonvertebral fractures included age, estrogen use, number of medications, rheumatoid arthritis diagnosis, and history of nonvertebral fractures. Model for hip fractures included age, estrogen use, number of medications, and history of hospitalization.

\section{Discussion}

In this observational study across multiple US health plans, we observed that patients on once-a-week dosing of risedronate had a lower incidence of hip and nonvertebral fractures than patients on once-a-week dosing of alendron- ate. Differences in fracture incidence between these two cohorts of patients were observed at 6 and 12 months after initiating therapy.

As with all observational studies, systematic errors (e.g., selection bias, measurement misclassification) may be the basis for the observed results [26]. In this study, systematic
Fig. 4 Cumulative incidence of hip fractures in patients treated with alendronate or risedronate for up to 1 year

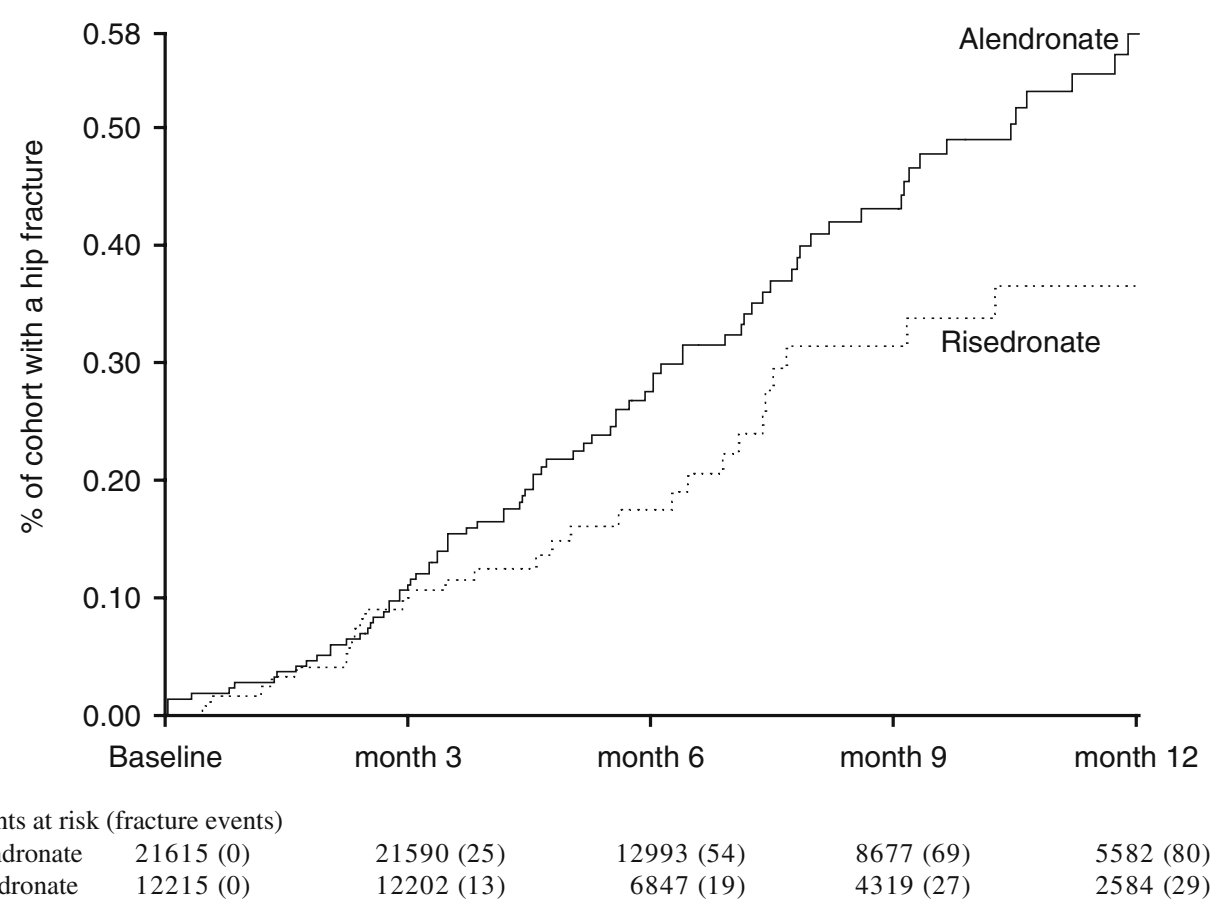


Fig. 5 Sensitivity analysis: Rate ratio for fracture in the first year of therapy between patients on risedronate and patients on alendronate; results of the primary analysis and 4 other methods of analyses
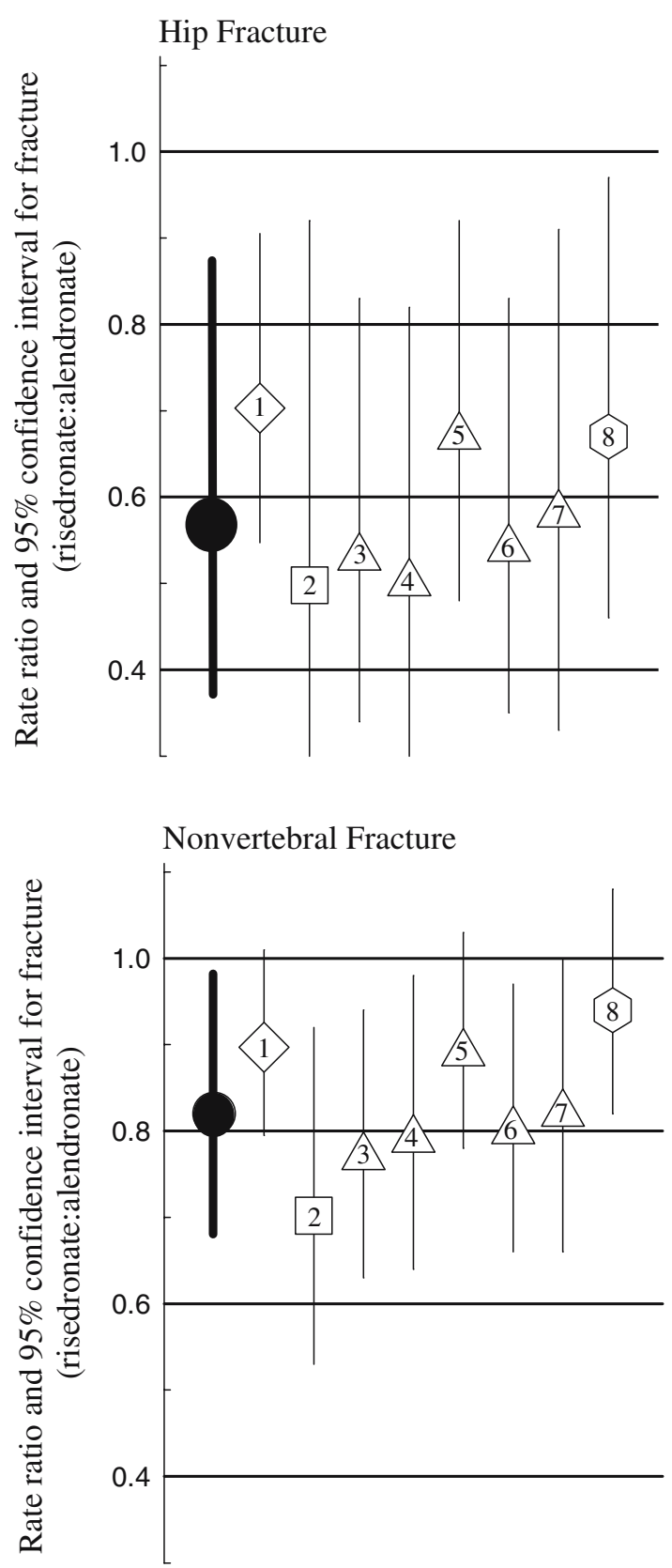

\section{Symbol legend for method of analysis}

- Primary analysis $(n=33,830)$ that followed subjects during their therapy, where the number of study outcomes was $\mathrm{n}=109$ hip fractures and $\mathrm{n}=507$ nonvertebral fractures; proportional hazard modeling to adjust for differences in baseline characteristics of fracture risk

Intent-to-treat analysis

1) Intent to treat analysis $(n=33,830+$ 17,329) that included all subjects with at least 1 prescription and no censoring for an end in therapy adherence

Propensity analysis

2) Propensity analysis $(n=33,830)$ for statistical adjustment of differences in baseline fracture risk

Change in inclusion criteria for the study population

3) Excluded subjects $(n=33,830$ - 3,086) with historical use of steroids

4) Excluded subjects $(n=33,830$ $9,505)$ with historical use of estrogen, calcitonin, or raloxifene

5) Added subjects $(n=33,830+43,032)$ having a history period of less than 6 months

6) Excluded subjects $(n=33,830-1,768)$ using alendronate $35 \mathrm{mg}$

7) Excluded subjects $(\mathrm{n}=33,830$ $2,235)$ with a clinical diagnosis of hip, nonvertebral, or vertebral fracture during the 6 month period before bisphosphonate therapy

Change in inclusion criteria for the study outcome

8) Analysis ( $n=33,830)$ with no exclusion of any medical claims for a fracture, hence the number of outcomes was $\mathrm{n}=135$ hip fractures and $\mathrm{n}=923$ nonvertebral fractures errors may arise from differences in fracture risk between the 2 cohorts of patients at initiation of therapy. Between the two cohorts, there were statistical differences in measurable fracture risk characteristics (Table 2), there are likely to be differences in known fracture risk characteristics not available within medical claims data (e.g., bone mineral density, family history, smoking history), and there are likely to be differences in unknown fracture risk characteristics (i.e., those that are controlled through randomized trials). The differences in measurable fracture risk characteristics, for which a greater percentage of the risedronate cohort has risk factors for fracture than the alendronate cohort suggesting bias towards higher fracture rates in the risedronate cohort, are inconsistent with observed results. The near unity in fracture incidence between the two cohorts during the first 3 months of therapy (Figs. 3 and 4) - a period for which there is also unity in fracture incidence between bisphosphonate therapy and placebo in clinical trials [12, 14] - suggest that both cohorts had similar risk for fracture at initiation of therapy. However, differences in fracture risk at initiation of therapy between the two cohorts cannot be excluded. 
Within healthcare utilization data, which are collected for purposes other than research, misclassification of fracture events and of therapy use are inevitable. As a check on the data, the rate of fracture events and therapy use of these health utilization data are in agreement with other data sources. In the current study, the annual fracture rates following initiation of therapy $(\approx 2.0 \%$ for nonvertebral fractures and $\approx 0.5 \%$ for hip fractures) are consistent with the annual rates in the treated population of clinical trials (between 2.0 and $2.3 \%$ for nonvertebral fractures and between $0.4 \%$ and $0.7 \%$ for hip fractures $[6-10,27])$. In this study, risedronate patients constituted $25 \%[45,360 /$ $(45,360+137,412)]$ of the bisphosphonate users in the utilization data compared to $24 \%$ [13.6 million / (13.6 million +44.1 million)] of all bisphosphonate prescriptions in the US during the same period [28]. A good method for evaluating misclassification within healthcare utilization data is through a medical chart review. In a prior study, the proportion of fracture claims confirmed by chart review to be a fracture was highest for the hip relative to other fracture sites [29]. Since the effect of misclassification at these other fracture sites is likely to be no different between cohorts (i.e., misclassified exposure does not depend on cohort status), the study results for nonvertebral outcomes are likely more attenuated by misclassification than results for the hip [30].

The strength of observational studies can be the generalizability of results. In contrast, the generalizability of results from randomized trials to a real world setting can be limited by differences between the two in relation to expertise of health care provider, quality of medical care, course of therapy, and types of patients [31]. For example, it has been observed that the majority of patients considered candidates for osteoporosis therapy by their physician would not meet the eligibility criteria for inclusion in the randomized trials [32]. Since the population within the current observational study is drawn from multiple health plans in many US states and consists of subjects with a mixture of health characteristics (e.g., prior gastrointestinal comorbidities), the results are likely to be generalizable. Furthermore, the length of observation of therapy adherence $(\approx 232$ days) in the current study was consistent to the previously reported average duration of adherence to bisphosphonate therapy (245 days) [33].

In conclusion, within this observational study of clinical practice, a cohort of patients receiving risedronate had lower rates of hip and nonvertebral fractures during their first year of therapy than a cohort of patients receiving alendronate. These results do not appear to be explained by baseline differences in fracture risk between cohorts. In addition, the observed rates of fracture were consistent with the fracture rates in clinical trials. Thus it appears, patients receiving risedronate are better protected from hip and nonvertebral fractures during their first year of therapy than patients receiving alendronate.

Financial Disclosures Drs. Silverman, Watts, Delmas, and Lindsay have received consulting fees, lecture fees, or research grants from The Alliance for Better Bone Health (Procter \& Gamble Pharmaceuticals and sanofi-aventis). Dr. Lange is an employee of Procter \& Gamble Pharmaceuticals.

Support The data source for this article was leased by The Alliance for Better Bone Health. Every author had full access to all of the data and takes responsibility for the integrity of the data and the accuracy of the data analysis.

\section{References}

1. U.S. Department of Health and Human Services (2004) Bone Health and Osteoporosis: A Report of the Surgeon General. U.S. Department of Health and Human Services, Office of the Surgeon General, Rockville, MD

2. Tosteson A, Solomon D, King AB, Dawson-Hughes B, Burge R, Wong J (2005) Projections of osteoporosis fractures and costs by skeletal sites in the USA. ASBMR 27th annual meeting, Nashville, TN

3. Melton LJ 3rd, Crowson CS, O'Fallon WM (1999) Fracture incidence in Olmsted County, Minnesota: comparison of urban with rural rates and changes in urban rates over time. Osteoporos Int 9:29-37

4. U.S. Preventive Services Task Force (2002) Screening for Osteoporosis in Postmenopausal Women: Recommendations and Rationale. Agency for Healthcare Research and Quality, Rockville, MD

5. Stafford RS, Drieling RL, Hersh AL (2004) National trends in osteoporosis visits and osteoporosis treatment, 1988-2003. Arch Intern Med 164:1525-1530

6. Harris ST, Watts NB, Genant HK et al (1999) Effects of risedronate treatment on vertebral and nonvertebral fractures in women with postmenopausal osteoporosis: a randomized controlled trial. Vertebral Efficacy With Risedronate Therapy (VERT) Study Group. JAMA 282:1344-1352

7. Reginster J, Minne HW, Sorensen OH et al (2000). Randomized trial of the effects of risedronate on vertebral fractures in women with established postmenopausal osteoporosis. Vertebral Efficacy with Risedronate Therapy (VERT) Study Group. Osteoporos Int 11:83-91

8. Liberman UA, Weiss SR, Broll J et al (1995) Effect of oral alendronate on bone mineral density and the incidence of fractures in postmenopausal osteoporosis. The Alendronate Phase III Osteoporosis Treatment Study Group. N Engl J Med 333:1437-1443

9. Black DM, Cummings SR, Karpf DB et al (1996) Randomised trial of effect of alendronate on risk of fracture in women with existing vertebral fractures. Fracture Intervention Trial Research Group. Lancet 348:1535-1541

10. Cummings SR, Black DM Thompson DE et al (1998) Effect of alendronate on risk of fracture in women with low bone density but without vertebral fractures: results from the Fracture Intervention Trial. JAMA 280:2077-2082

11. Chesnut III CH, Skag A, Christiansen C et al (2004) Effects of oral ibandronate administered daily or intermittently on fracture risk in postmenopausal osteoporosis. J Bone Miner Res 19:1241-1249

12. Harrington JT, Ste-Marie LG Brandi ML et al (2004) Risedronate rapidly reduces the risk for nonvertebral fractures in women with postmenopausal osteoporosis. Calcif Tissue Int 74:129-135

13. Pols HA, Felsenberg D, Hanley DA et al (1999) Multinational, placebo-controlled, randomized trial of the effects of alendronate 
on bone density and fracture risk in postmenopausal women with low bone mass: results of the FOSIT study. Foxamax International Trial Study Group. Osteoporos Int 9:461-468

14. Black DM, Thompson DE, Bauer DC et al (2000) Fracture risk reduction with alendronate in women with osteoporosis: the Fracture Intervention Trial. J Clin Endocrinol Metab 85:4118-4124

15. Nancollas GH, Tang R, Phipps RJ, et al (2006) Novel insights into actions of bisphosphonates on bone: differences in interactions with hydroxyapatite. Bone 38:617-627

16. Rosen CJ, Hochberg MC, Bonnick SL et al; Fosamax Actonel Comparison Trial Investigators (2005) Treatment with onceweekly alendronate $70 \mathrm{mg}$ compared with once-weekly risedronate $35 \mathrm{mg}$ in women with postmenopausal osteoporosis: a randomized double-blind study. J Bone Miner Res 20:141-151

17. Watts NB, Geusens P, Barton IP, Felsenberg D (2005) Relationship between changes in BMD and nonvertebral fracture incidence associated with risedronate: reduction in risk of nonvertebral fracture is not related to change in BMD. J Bone Miner Res 20:2097-2104

18. Hochberg MC, Greenspan S, Wasnich RD, Miller P, Thompson DE, Ross PD (2002) Changes in bone density and turnover explain the reductions in incidence of nonvertebral fractures that occur during treatment with antiresorptive agents. J Clin Endocrinol Metab $87: 1586-1592$

19. Klungel $\mathrm{OH}$, Martens EP, Psaty BM et al (1995) Methods to assess intended effects of drug treatment in observational studies are reviewed. J Clin Epidemiol 57:1223-1231

20. Psaty BM, Heckbert SR, Koepsell TD et al (1995) The risk of myocardial infarction associated with antihypertensive drug therapies. JAMA 274:620-625

21. Zhou Z, Rahme E, Abrahamowicz M et al (2005) Effectiveness of statins for secondary prevention in elderly patients after acute myocardial infarction: an evaluation of class effect. CMAJ 172:1187-1194

22. Watts NB, Worley K, Solis A, Doyle J, Sheer R (2004) Comparison of risedronate to alendronate and calcitonin for early reduction of nonvertebral fracture risk: results from a managed care administrative claims database. J Manag Care Pharm 10:142-151
23. Peng RD, Dominici F, Zeger SL (2006) Reproducible epidemiologic research. Am J Epidemiol 163:783-789

24. Strengthening the reporting of observational studies in epidemiology (STROBE). Available at http://www.strobe-statement.org. Accessed 14 June 2006

25. Sikka R, Xia F, Aubert RE (2005) Estimating medication persistency using administrative claims data. Am J Manag Care $11: 449-457$

26. Grimes DA, Schulz KF (2002) Bias and causal associations in observational research. Lancet 359:248-252

27. McClung MR, Geusens P, Miller PD et al (2001) Effect of risedronate on the risk of hip fracture in elderly women. Hip Intervention Program Study Group. N Engl J Med 344:333340

28. IMS Health, National Prescription Audit Plus, Plymouth Meeting, PA

29. Ray WA, Griffin MR, Fought RL, Adams ML (1992) Identification of fractures from computerized Medicare files. J Clin Epidemiol 45:703-714

30. Kelsey JL, Thompson WD, Evans AS (1986) Methods in Observational Epidemiology. Oxford University Press, Oxford

31. Black N (1996) Why we need observational studies to evaluate the effectiveness of health care. BMJ 312:1215-1218

32. Dowd R, Recker RR, Heaney RP (2000) Study subjects and ordinary patients. Osteoporos Int 11:533-536

33. McCombs JS, Thiebaud P, McLaughlin-Miley C, Shi J (2004) Compliance with drug therapies for the treatment and prevention of osteoporosis. Maturitas 48:271-287

34. McEvoy GK (ed) (2005) AHFS Drug Information 2005. American Society of Health-System Pharmacists, Bethesda, MD

35. Kane S, Borisov NN, Brixner D (2004) Pharmacoeconomic evaluation of gastrointestinal tract events during treatment with risedronate and alendronate: a retrospective cohort study. Am J Manag Care 10:S216-S226

36. Miller RG, Bolognese M, Worley K, Solis A, Sheer R (2004) Incidence of gastrointestinal events among bisphosphonate subjects in an observational setting. Am J Manag Care 10:S207S215 